\title{
The Effect of Mood on Post-Operative Pain and the Reliability and Validity of the Wisconsin Brief Pain Questionnaire Adapted on Black South Africans
}

\section{Esther Queen Mokhuane}

Department of Clinical Psychology, University of Limpopo, Medunsa Campus, Box 110, P. O. Medunsa, 0204, South Africa

\begin{abstract}
Pain is a multidimensional phenomenon and the primary objective of all assessment tools is to gather accurate, subjective and objective information relevant to the pain that the patient is experiencing. This information plays a vital role in the diagnostic process and the treatment given to the patient. Thus it is of paramount importance that these pain measures are valid and reliable. Measures of pain are predominately developed in Western countries. This study investigated pre-surgical moods and their effect on acute pain following surgery including the reliability and validity of the Profile of Mood State (POMS), Visual Analogue Scale (VAS) and Wisconsin Brief Pain Questionnaire (WBPQ). These measures in particular have been developed in the United States of America and had to be adapted to the South African context using Setswana-speaking participants at George Mukhari Hospital formerly known as Ga-Rankuwa Hospital in South Africa. A biographical questionnaire was developed by the researcher for gathering background information of the participants. The POMS and the WBPQ were translated from English to Setswana using back-translation and were administered to a sample of 58 patients pre-operatively. VAS and WBPQ were administered post-operatively. The POMS was administered to determine the relationship of mood states to postoperative pain. Correlations were calculated between the six mood states scales that showed acceptable reliability but divergent validity was not confirmed. Concurrent and predictive validity between VAS and WBPQ was high and both measures have reasonable repeated-measures reliability.
\end{abstract}

Keywords: Assessment of moods; Measures of pain; Validity; Reliability; WBPQ; VAS; POMS

\section{Introduction}

[1-4] suggested that cognitive-evaluative and motivational-affective factors interacted with sensory phenomena to create pain perception. The emotional state of the individual can contribute extensively to the experience of pain. Pain usually occurs with negative mood states such as anxiety, anger, irritability, depression and fear [6-10]. These psychological factors determine pain experience to a large extent and have received considerable attention in Western countries which is unmatched in non-Western countries [11]. Pre-operative anxiety has been recognised as a significant predicator of post-operative pain $[12,13]$. Pre-operative anxiety has its roots in the patients' anticipation of pain during surgical procedures.

The aforementioned negative moods may have a detrimental effect on the patients' abilities to cope with pain or may increase his or her perception of pain. From this perspective, it is essential that mood or affect be assessed as it is believed to be related to an individual's perception of pain.

Severe post-operative pain has been recorded using the Visual Analogue Scale (VAS) developed by [14] and the Wisconsin Brief Pain Questionnaire (WBPQ). The WBPQ which was developed by $[15,16]$ has been used extensively in the measurement of chronic pain. To date, there is no measure that has used the WBPQ to measure postoperative pain. The strength of the VAS is its demonstrated validity and reliability as a measure of pain intensity and it is also sensitive to treatment effects [17-19].

The WBPQ appears to have adequate reliability and validity when assessing chronic pain and arthritis [16]. The psychological distress of the patient was measured by means of Profile of Mood States (POMS) developed by [20]. The reliability and validity of the POMS were established by several investigators [20-22]. Furthermore, research by
[23] has shown that pain intensity correlates weakly but positively with negative mood. The primary objective of this study is to assess presurgical moods and its effect on post-operative pain and to establish the reliability and validity of the WBPQ in assessing acute pain.

\section{Methods}

\section{Recruitment of participants}

Participants were recruited from the obstetrics and gynaecology wards. A name of list of patients who were likely to undergo surgery was drawn up by the nurses in the ward. The researcher used this name list to select participants for the study. Selective random sampling was used. Every fourth patient on the ward list scheduled for laparotomy was selected as they came into the wards.

\section{Selection criteria}

After being selected, the researcher had to establish from the participants if they spoke Setswana or Northern Sotho and those that did, were requested to participate in the study. All the participants had to be at least 18 years old to be admitted in the study. The participants had to have had pain in the past month and at present; the participants

Corresponding author: Esther Queen Mokhuane, Department of Clinical Psychology, University of Limpopo, Medunsa Campus, Box 110, P. O. Medunsa, 0204, South Africa; Tel: +2712 521 4072; Fax: +2712 521 4072; E-mail: tlhoki@ worldonline.co.za

Received April 08, 2011; Accepted June 30, 2011; Published July 06, 2011

Citation: Mokhuane EQ (2011) The Effect of Mood on Post-Operative Pain and the Reliability and Validity of the Wisconsin Brief Pain Questionnaire Adapted on Black South Africans. J Neurol Neurophysiol 2:113. doi:10.4172/2155-9562.1000113

Copyright: (C) 2011 Mokhuane EQ. This is an open-access article distributed under the terms of the Creative Commons Attribution License, which permits unrestricted use, distribution, and reproduction in any medium, provided the original author and source are credited. 
had to have been examined and diagnosed by the ward obstetriciangynaecologist as candidates for laparotomy. The anaesthetist had to confirm their booking for the operation.

\section{Sample}

The sample consisted of 58 female patients who were admitted to the obstetrics and gynaecology wards for a laparotomy. The ages of the participants ranged from 18 to 56 with the mean age of 32.2 years. Thirty three (56\%) of the participants had primary school education (no education to eight years of schooling). The remaining twenty five (44\%) had secondary school education with $14 \%$ having completed high school education.

As far as their medical history is concerned, $65.5 \%$ of the participants had visited the doctor or the hospital within the last 12 months, $53.4 \%$ had been previously admitted to a hospital, and $37.9 \%$ of the participants had previous laparotomies. None of the participants reported previous psychiatric illness.

Apart from the visit to the doctors, an inquiry was made into the degree of pain experienced by the participants over the past month as well as the effect it might have had on their functioning.

\section{Materials}

Three questionnaires were used, namely: POMS (refer to appendix A), VAS (refer to appendix B) and the WBPQ (refer to appendix C).

\section{The Profile of Mood States (POMS)}

POMS is a standardised checklist consisting of 65 adjectives, used to measure the following transient mood states: tension, fatigue, depression, confusion, anger and vigor. A five-point verbal-numerical rating scale is employed to measure mood intensity. The participant chooses a verbal descriptor which is then scored as follows:

$$
\begin{aligned}
& 0=\text { not at all } \\
& 1=\text { a little } \\
& 2=\text { moderately } \\
& 3=\text { quite a bit } \\
& 4=\text { extremely }
\end{aligned}
$$

Factor analytic studies of POMS have found six interrelated factors, namely: tension-anxiety, fatigue-inertia, vigor-activity, confusionbewilderment, depression-dejection and anger-hostility [20]. A score is obtained for each factor by summing the values given to the relevant adjectives within the factor. Since the items are randomly positioned, overlays are used to determine the six subscale scores. A Total Mood Disturbance (TMD) score may be calculated by summing the scores across the six factors with 'vigor-activity' weighted negatively.

The current study uses the Profile of Mood States to assess psychological attributes (mood) of pain patients. The use of this measure follows from the assumption borne out repeatedly in the clinical and empirical literature that pain is a somatopsychic phenomenon and that patient's psychological status has important implications for the planning, implementation and outcome of treatment.

\section{VAS (Visual Analogue Scale)}

VAS is a simple method of quantifying self-rated pain intensity. The scale is completed by the patient who is asked to draw a line at the mark that represents the level of pain experienced. VAS has high test- retest reliability and it correlates with other measures of pain intensity [24-27,17].

VAS has been criticised for measuring pain as though it is unidimensional, with specific reference to intensity. Despite the fact that VAS is easily understood by most patients, not all patients can complete it and this is evident in the study discussed below. The scale imposes limits by making the extremes absolute with measures such as "no pain" and "complete relief", however the other anchor is not. For example, the "the worst pain one can imagine" leaves no room for even worse pain at a later time. Responses to the VAS are influenced by various biases affecting psychophysical measures [28-30]. The VAS requires a certain amount of coordination, which may be lacking in the post-operative period and measurements may be difficult to perform after anaesthesia when the patient may experience concentration problems.

It is acknowledged that VAS is one of the subjective methods used to measure pain intensity. However, according to recent research the use of VAS in elderly people is associated with higher failure of completion rate and that elderly people prefer NRS than VAS [31]. Due to the fact that this was based on cancer patients, it can be assumed that VAS is less suitable for evaluating pain in cancer patients who are assumed to be older. This is despite the fact that VAS has shown better sensitivity to change. It is worth emphasizing that this conclusion with respect to the suitability of VAS in cancer was based on elderly people, which means that age plays a role in the completion of this tool.

\section{Wisconsin Brief Pain Questionnaire (WBPQ)}

The WBPQ was developed specifically to assess pain in cancer patients. WBPQ contains 17 questions, it is self-administered, easily understood and has a high completion rate unless the patient is very sick. It assesses relevant pain data such as the current manifestation of pain, its location, its intensity, quality whereby patients use their own words to describe their pain; consequently allowing the patient to give the clinician his or her subjective description of his or her experience of pain. It also assesses history of the pain, pain relief and its interference with mood, enjoyment of life and everyday activities. It uses pain drawing and verbal numeric scale, patients rate their pain now and when it is at average and worst. WBPQ uses the rating scale ranging from $0-10$ with 0 as 'no pain'. Like all instruments, WBPQ has its flaws, one of which is that it does not measure the emotional significance of pain or its influence on the patient's life.

The POMS and WBPQ were not specially developed for South African adults. Thus both these questionnaires were translated into Setswana prior to the commencement of this study.

When the various questions of the WBPQ and the POMS are considered, it can be seen that they require participants to be verbally analytic as far as their personal experience with pain and mood are concerned. The POMS could be challenging to participants who are without any formal education. However, the POMS and the WBPQ were administered individually, so that the researcher could establish rapport with each subject and address any problems that arose from the participants not understanding the questionnaire.

Tests should use a form of language that is widely familiar. South African participants may have difficulty understanding some American phrases. The majority of participants used in this study have a primary school education in their mother tongue (Setswana). For those participants who have had a more extensive formal education (high school and university education) English is their second language, but 
even for them words such as "peeved", "bushed" and "grouchy" may be meaningless or have different connotations. A standard English dictionary was used to find equivalents for these words without altering their meaning.

The question: "During the past week how much did the state of your health including any pain, interfere with....enjoyment of life," could also present some problems. The words "enjoyment of life" undoubtedly evoke very different images for the impoverished participants than they do for the middle-class participants. This may make cross-cultural and interclass comparisons less meaningful.

Since some of the items of the WBPQ are non-verbal in nature, few adaptations were required. The only changes that had to be made in items $6,7,8$ and 10, where a drawing more like a speedometer was used to indicate the levels of average pain, worst pain, pain now and pain relief. The participant indicates her pain by placing the pointer in the area of her choice. No pain is on the extreme left side and estimates of the intensity of pain increase as one move the pointer to the right side of the scale. The same procedure applies to indications of pain relief.

\section{Translation}

Three trilingual clinicians with post-graduate qualification, one in psychiatry and two in clinical psychology and a bilingual professional teacher who was at the time studying a masters degree in Setswana, were employed to translate the questionnaires. One clinician uses Northern Sotho as her primary language (mother tongue) as a result she did the translations into Northern Sotho.

A Setswana-speaking clinician and the Setswana-speaking teacher were employed to translate both the POMS and WBPQ into Setswana. The third clinician who is trilingual, blindly translated the questionnaires back from Setswana into English and from NorthernSotho into English. The three English versions were then compared and where differences were found, they were discussed and resolved. Finally, an independent clinical psychologist who is trilingual checked the translations against the originals.

To determine the suitability of the language used, the translators were asked to analyse each item of the WBPQ and the POMS to ensure that the language is understandable. There was consensus among the translators with reference to the language used that it was understandable and that the instructions were clear.

\section{Test administration}

In Western settings these questionnaires are usually given to participants to complete at a time of their choice. In South Africa however, due to the high rate of illiteracy the questionnaires cannot be given to the subject to complete at his or her own leisure time because there is no guarantee that the subject has read or understood the items or that the replies are his or her own.

In an attempt to reduce these difficulties, all questionnaires were administered individually and orally, with the interviewer holding one copy of the questionnaire and the subject holding another, presumably reading it. The subject was asked to give responses to the questions posed to her by the interviewer. Where participants needed clarification, every effort was made to sound completely neutral and not to give unusual emphasis to any word in the items. The replies were recorded by the interviewer on her own blank page with the participants name on it. To reduce reluctance on the part of the subject to speak freely, especially during the administration of the WBPQ, the subject was frequently reassured by the interviewer that there were no right or wrong answers and that her views were sought.
Each subject was requested to supply the researcher/interviewer with biographical information (see appendix D) pertaining to his or her name, age, home address, gender, standard of education, marital status, dependants and past medical history.

\section{Procedure}

After obtaining informed consent from the participants, the study was explained to the participant as a study on the measurement of pain and moods and assessing both the history and severity of pain. The interviews were conducted by the researcher at the bedside of the participant (patient) using the POMS, VAS and the WBPQ.

The POMS was used to assess pre-operative moods. Mood assessments were done 24 hours before the operation to determine the relationship between pre-operative moods and post-operative pain. During this time the researcher presented the participants with the Profile of Mood States saying: "Here are words describing people's feelings. I would like to find out how you have been feeling during the past week and at present." "I will read each item to you and you should indicate to me whether the information applies to you or not by giving one of the following responses: not at all, a little, quite a bit, moderately and extremely. I will assign a score for you ranging from 0 to 4 depending on the phrases you have used to describe your feeling."

After the laparotomy, on average pethedine hydrochloride $100 \mathrm{ml}$ was given intramuscularly 6 hourly $\mathrm{x} 6$ doses for one and a half days for alleviating post-operative pain. The drug works at its peak during the first 30 to 60 minutes after administration. The half-life of the drug is regarded as two to three hours after administration, but factors such as body weight affect its metabolism.

The pain assessments were done at the following times after the operation (it should be noted that these pain assessments are explained in detail under results:

\section{Day 1}

No medication- when patients arrived in the wards from the theatre and were without pain medication.

Medication peak- 30 minutes after medication, when the subject could be considered to be under optimal pain medication.

\section{Day 2}

Trough level- when pain medication could be considered to have worn off.

Medication peak- when pain medication could be considered to be optimal in its effects.

\section{Analysis of data}

The POMS data consisted of the responses of 58 laparotomy patients. To determine the reliability and validity of the POMS, the answers to the POMS were collected for each of the 58 laparotomy patients/participants. This data was subjected to a scale analysis in an attempt to verify the six-scale structure of the POMS. On the basis of this scale analysis it was then decided whether other scales should be derived. Subsequently the internal consistency reliabilities were computed for all six factors as well as for newly derived factors or scales. Correlations between all scales were computed.

To determine the relationship of mood states to post-operative pain, correlations were calculated between all mood state scales which 
showed acceptable validity and reliability, and post-operative pain measures as given by the VAS and WBPQ.

The reliability of the pain measures (the VAS and WBPQ) were calculated as test-retest reliabilities by correlating measures of day 1 with measures of day 2. A comparison of the mean pain level before and after pain medication was also performed for measures taken on day 1 and day 2 in order to evaluate the validity of the VAS and WBPQ. Finally, the VAS measures correlated with WBPQ scores of the same occasion to establish the concurrent validity of these pain measure instruments. The level of significance used was 0.05 .

\section{Results}

\section{Medical history of the participants}

The medical history of the participants with reference to past operations and pain experience is summarised in Table 1.

More than $72 \%$ of the patients indicated "no pain" (as measured by the VAS) while more than $84 \%$ indicated that the pain had not been troublesome. It can be concluded that, in general, laparotomy patients do not indicate severe levels of pain or pain affecting their daily activities prior to the laparotomy.

\section{Reliability and validity of the POMS}

As discussed previously, the POMS consists of 65 items and

\begin{tabular}{|l|l|}
\hline Symptom or incident & Yes $\%$ \\
\hline Seen doctor or visited hospital in last 12 months? & $65.5 \%$ \\
\hline Admitted within the last 12 months? & $53.4 \%$ \\
\hline Previous laparotomy? & $37.9 \%$ \\
\hline Psychiatric illness? & $00.0 \%$ \\
\hline Pain at onset of illness? & $25.9 \%$ \\
\hline Pain present at diagnosis? & $43.1 \%$ \\
\hline Pain at any time during the present illness? & $24.1 \%$ \\
\hline Pain during the last month? & $6.9 \%$ \\
\hline
\end{tabular}

Table 1: Medical history of the 58 laparotomy patients.

\begin{tabular}{|l|l|}
\hline Factor & Cronbach Alpha \\
\hline Tension-Anxiety & 0.87 \\
\hline Depression-Dejection & 0.94 \\
\hline Anger-Hostility & 0.91 \\
\hline Vigor-Activity & 0.89 \\
\hline Fatigue-Inertia & 0.89 \\
\hline Confusion-Bewilderment & 0.85 \\
\hline
\end{tabular}

Table 2: Reliability of the factors of the POMS: Cronbach alpha coefficients $(\mathrm{N}=58)$.

\begin{tabular}{|l|}
\hline VAS1 (before) 9.151 .63 \\
\hline VAS2 (after) 0.200 .52 \\
\hline VASDIF1 (difference) 8.941 .605742 .450 .0001 \\
\hline VAS3 (before) 8.172 .27 \\
\hline VAS3 (after) 0.290 .97 \\
\hline VASDIF2 (difference) 7.872 .415724 .850 .0001 \\
\hline WBPQ1 (before) 163.9431 .87 \\
\hline WBPQ2 (after) 5.0011 .31 \\
\hline WBPQDIF1 (difference) 158.9431 .365738 .590 .0001 \\
\hline WBPQ3 (before) 148.2745 .14 \\
\hline WBPQ4 (after) 3. 0812.00 \\
\hline WBPQDIF2 (difference) 145.1845 .065724 .530 .0001 \\
\hline
\end{tabular}

Variable Mean SD DF t p-value

Table 3: A comparison of pain with and without medication. as measured with the VAS and the WBPQ. purports to measure six mood scales. The POMS was administered to each of these 58 laparotomy patients individually. 24 hours before the laparotomy was performed. The responses were subjected to an item analysis and Cronbach Alpha coefficients and were computed for each of the six scales $[32,33]$. These coefficients are measures of the internal consistency (reliability) of the factors and are reported in Table 2.

The internal consistency is acceptably high for each of the factors and compares favourably with values reported by other researchers $[34,20]$. To answer the question concerning the construct validity of these factors. This study computed scores for each factor of the 58 patients and then calculated the intercorrelations between these factors. The intercorrelations were found to be high between all the scales. except with vigor-activity. When vigor-activity is excluded. intercorrelations varied from 0.70 to 0.91 . The intercorrelations with vigor-activity varied from 0.09 to 0.33 . It is apparent that the intercorrelations are high for five factors except for vigor-activity.

A subsequent factor analysis performed on the intercorrelations matrix confirmed that. except for vigor-activity. all the other six factors might be combined to form a single "second-order" factor. One might conclude from these results that the present study could not demonstrate sufficient discriminate/divergent validity for the different factors of the POMS. In fact the Cronbach Alpha computed for five of the factors combined (treating the items in the factors as if they are items in a single test) was found to be 0.98 which is very high. It was decided to calculate such a combined score for the five factors for each patient and call this factor a "general mood factor." The factor vigoractivity is however retained as a separate factor.

\section{Reliability and validity of the VAS and WBPQ}

These two measures (VAS and WBPQ) have been discussed above. In this study these two instruments were applied to each of the 58 laparotomy patients post-operatively and individually. as follows:

Day 1: No medication-immediately after the operation when patients could be considered to be without medication or effects of pain medication prior to the operation might have worn off. These measures will be called VAS1 and WBPQ1 and are "no pain medication" measures of pain.

At medication peak 30 minutes after medication. when the patients could be considered to be under optimal pain medication. These measures will be called VAS2 and WBPQ2 and are "under pain medication" measures of pain.

Day 2: During medication trough, 6 to 7 hours after pain medication when the effects of pain medication administered previously should have worn off. These measures are called VAS3 and WBPQ3.

At medication peak 30 minutes after pain medication when the participants could be considered to be under optimal pain medication. These measures will be called VAS4 and WBPQ4.

Table 3 compares the "no-pain medication" measures to the "under pain medication" measures by performing t-tests for dependent measures on the differences between "before" and "after" pain medication pain measures.

From the table it is clear that pain medication (pethidine) results in a significant decrease in pain as measured by the VAS and the WBPQ, proving the predictive validity of both measures. The question now arises as to how the pain measures of the VAS and WBPQ correlate. These correlations are given in Table 4. 


\begin{tabular}{|c|c|c|c|c|c|c|c|c|c|c|c|c|}
\hline TEST & VAS 1 & VAS 2 & VAS 3 & VAS 4 & WBPQ 1 & WBPQ 2 & WBPQ 3 & WBPQ 4 & $\begin{array}{l}\text { VAS- } \\
\text { DIF } 1\end{array}$ & $\begin{array}{l}\text { VAS- } \\
\text { DIF } 2\end{array}$ & $\begin{array}{l}\text { WBPQ- } \\
\text { DIF } 1\end{array}$ & $\begin{array}{l}\text { WBPQ- } \\
\text { DIF } 2\end{array}$ \\
\hline VAS 1 & 1.000 & & & & & & & & & & & \\
\hline VAS 2 & $\begin{array}{l}0.209^{1} \\
0.115^{2}\end{array}$ & 1.000 & & & & & & & & & & \\
\hline VAS 3 & $\begin{array}{l}0.813 \\
0.000\end{array}$ & $\begin{array}{l}0.190 \\
0.151\end{array}$ & 1.000 & & & & & & & & & \\
\hline VAS 4 & $\begin{array}{l}0.103 \\
0.439\end{array}$ & $\begin{array}{l}0.016 \\
0.901\end{array}$ & $\begin{array}{l}0.071 \\
0.592\end{array}$ & 1.000 & & & & & & & & \\
\hline WBPQ 1 & $\begin{array}{l}0.901 \\
0.000\end{array}$ & $\begin{array}{l}0.203 \\
0.126\end{array}$ & $\begin{array}{l}0.762 \\
0.000\end{array}$ & $\begin{array}{l}0.029 \\
0.823\end{array}$ & 1.000 & & & & & & & \\
\hline WPBQ 2 & $\begin{array}{l}0.219 \\
0.097\end{array}$ & $\begin{array}{l}0.472 \\
0.000\end{array}$ & $\begin{array}{l}0.199 \\
0.132\end{array}$ & $\begin{array}{l}0.014 \\
0.915\end{array}$ & $\begin{array}{l}0.222 \\
0.092\end{array}$ & 1.000 & & & & & & \\
\hline WBPQ 3 & $\begin{array}{l}0.853 \\
0.000\end{array}$ & $\begin{array}{l}0.167 \\
0.203\end{array}$ & $\begin{array}{l}0.886 \\
0.000\end{array}$ & $\begin{array}{l}0.121 \\
0.361\end{array}$ & $\begin{array}{l}0.823 \\
0.000\end{array}$ & $\begin{array}{l}0.156 \\
0.242\end{array}$ & 1.000 & & & & & \\
\hline WBPQ 4 & $\begin{array}{l}0.135 \\
0.310\end{array}$ & $\begin{array}{l}0.064 \\
0.632\end{array}$ & $\begin{array}{l}0.168 \\
0.205\end{array}$ & $\begin{array}{l}0.874 \\
0.000\end{array}$ & $\begin{array}{l}0.051 \\
0.698\end{array}$ & $\begin{array}{l}-0.022 \\
0.886\end{array}$ & $\begin{array}{l}0.161 \\
0.225\end{array}$ & 1.000 & & & & \\
\hline $\begin{array}{l}\text { VAS- } \\
\text { DIF } 1\end{array}$ & $\begin{array}{l}0.948 \\
0.000\end{array}$ & $\begin{array}{l}-0.112 \\
0.339\end{array}$ & $\begin{array}{l}0.764 \\
0.000\end{array}$ & $\begin{array}{l}0.099 \\
0.456\end{array}$ & $\begin{array}{l}0.849 \\
0.000\end{array}$ & $\begin{array}{l}0.069 \\
0.604\end{array}$ & $\begin{array}{l}0.812 \\
0.000\end{array}$ & $\begin{array}{l}0.116 \\
0.382\end{array}$ & 1.000 & & & \\
\hline $\begin{array}{l}\text { VAS- } \\
\text { DIF } 2\end{array}$ & $\begin{array}{l}0.726 \\
0.000\end{array}$ & $\begin{array}{l}0.173 \\
0.139\end{array}$ & $\begin{array}{l}0.915 \\
0.000\end{array}$ & $\begin{array}{l}-0.335 \\
0.010\end{array}$ & $\begin{array}{l}0.708 \\
0.000\end{array}$ & $\begin{array}{l}0.182 \\
0.169\end{array}$ & $\begin{array}{l}0.787 \\
0.000\end{array}$ & $\begin{array}{l}-0.193 \\
0.145\end{array}$ & $\begin{array}{l}0.682 \\
0.000\end{array}$ & 1.000 & & \\
\hline $\begin{array}{l}\text { WBPQ- } \\
\text { DIF } 1\end{array}$ & $\begin{array}{l}0.836 \\
0.000\end{array}$ & $\begin{array}{l}0.036 \\
0.788\end{array}$ & $\begin{array}{l}0.703 \\
0.001\end{array}$ & $\begin{array}{l}0.025 \\
0.851\end{array}$ & $\begin{array}{l}0.936 \\
0.000\end{array}$ & $\begin{array}{l}-0.134 \\
0.314\end{array}$ & $\begin{array}{l}0.780 \\
0.000\end{array}$ & $\begin{array}{l}0.060 \\
0.649\end{array}$ & $\begin{array}{l}0.838 \\
0.000\end{array}$ & $\begin{array}{l}0.654 \\
0.000\end{array}$ & 1.000 & \\
\hline $\begin{array}{l}\text { WBPQ- } \\
\text { DIF } 2\end{array}$ & $\begin{array}{l}0.823 \\
0.000\end{array}$ & $\begin{array}{l}0.152 \\
0.254\end{array}$ & $\begin{array}{l}0.848 \\
0.000\end{array}$ & $\begin{array}{l}-0.110 \\
0.410\end{array}$ & $\begin{array}{l}0.816 \\
0.000\end{array}$ & $\begin{array}{l}0.163 \\
0.220\end{array}$ & $\begin{array}{l}0.964 \\
0.000\end{array}$ & $\begin{array}{l}-0.103 \\
0.440\end{array}$ & $\begin{array}{l}0.787 \\
0.000\end{array}$ & $\begin{array}{l}0.845 \\
0.000\end{array}$ & $\begin{array}{l}0.771 \\
0.000\end{array}$ & 1.000 \\
\hline
\end{tabular}

${ }^{1}$ Pearson product moment correlation

${ }^{2} \mathrm{P}$-value of correlation coefficient

Table 4: Correlations between VAS and WBPQ pain measure $(N=58)$, with $p$-values below the correlations.

From Table 4 the following results are noteworthy:

Good test-retest reliability is implied by the high correlations between VAS1 and VAS3 and between WBPQ1 and WBPQ3.

Concurrent validity is implied by the high correlations between VAS1 and WBPQ1 as well as between VAS3 and WBPQ3 (and to a lesser extent by the correlations between VAS2 and WBPQ2. and VAS4 and WBPQ4).

The relatively low correlations between VAS1, VAS2, VAS3 and VAS4. WBPQ1, WBPQ2 and between WBPQ3, WBPQ indicate that the degree of pain relief due to medication varies considerably from patient to patient.

\section{The relationship between pre-operative mood states and post-operative pain}

The general mood factor and vigor-activity factor scores obtained for each of the 58 patients pre-operatively were correlated with various post-operative VAS and WBPQ pain measures. As none of the correlations are close to significance, these correlations will not be reported here. It can be concluded that this study could not demonstrate any linear relationships between pre-operative mood states as measured by POMS and post-operative pain experience.

\section{Summary of results}

It was found in this study that the internal consistencies of the POMS were high but since the correlations between all the factors are very high (with the exception of vigor-activity). It could not be shown that the five factors deserve separate treatment. In this sense the individual factors of the POMS could not be shown to have construct validity.

The instruments used to measure pain, namely the VAS and the WBPQ do correlate highly with one another thus both demonstrating good reliability and concurrent validity. Also as far as measures of the VAS over time (VAS1 with VAS3; VAS2 with VAS4) and measures of the WBPQ over time (WBPQ1 with WBPQ3; WBPQ2 and WBPQ4) correlate highly. These measures have high test-retest reliabilities.

Measures of pain "under no medication" conditions (e.g. VAS1 and WBPQ1) appear to correlate relatively low with measures of pain under medication peak conditions (e.g. VAS2 and WBPQ2). Suggesting that the effect of pain medication on the degree of pain relief might vary considerably from patient to patient. Stated differently the relatively low correlations between "before medication" and "after medication" measures of pain might indicate that pain medication has a differential effect on patients, 5 . However, the fact that both pain measures strongly reflect the effect of pain medication proves them both to be valid instruments for assessing pain in Setswana and Northern Sesotho speaking participants.

Finally, pre-operative mood states (as measured by the POMS) were correlated with post-operative pain measures but no relationship could be demonstrated.

\section{Discussion}

\section{The reliability and validity of the POMS}

It was hypothesised that the POMS is a reliable and valid measure of mood in Setswana and Northern Sotho-speaking surgical patients undergoing laparotomy. And that the WBPQ is a reliable and valid measure of acute pain in both Setswana and Northern Sotho-speaking participants. The POMS and the WBPQ were translated into Setswana. The Cronbach Alpha coefficients for each of the mood factors of the POMS were found to be high. But unfortunately the correlations between five of the six factors (excluding vigor-activity) were also very high ranging from between 0.71 and 0.90 . The correlations found in this study appear to be too high to confirm the divergent validity of these factors. The high inter-correlations found between the five 
factors of the POMS. Suggest that these five factors might be combined to a form of a single "general mood" factor. The Cronbach Alpha was consequently calculated for such a scale consisting of all the items of these five factors and found to be 0.98 . It was decided to use this "general mood" factor and the "vigor-activity" factor for subsequent statistical comparisons between groups.

The lack of divergent validity of the POMS could possibly be attributed to the low educational standard of the participants, including participants without any formal education. Moods and pain are an integral experiences and it is possibly difficult for these individuals to isolate one specific emotion form all others. This ties in with an observation made by [35] in a study comparing psychiatrist's and patient's concepts of unpleasant emotions. He found that psychiatrists clearly differentiated between anxieties, depression and irritability as discrete types of emotional distress. While patients saw them as closely overlapping [35] to patients somatic symptoms such as palpitations. Excessive perspiration or shakiness were as characteristic of depression as of anxiety. In this study, this tendency might influence how patients respond to specific questions or phrases such as "anxious", "nervous" and "panicky".

\section{The reliability and validity of the WBPQ and the VAS}

The WBPQ and the VAS were applied post-operatively to the 58 laparotomy patients prior to the pain medication (no medication) and 30 minutes after pain medication was given (peak level). Thereafter the pain assessments were carried out at the trough level and peak level for two consecutive days including the day of surgery. The high correlations between repeated measurements on the WBPQ and the VAS indicate that both these measures have reasonable repeatedmeasures reliability. The high correlations between the WBPQ and the VAS measurements also indicate an acceptable concurrent validity for the WBPQ. Thus confirming previous findings [16].

Previous findings addressing the reliability and validity of the WBPQ concentrated on the measurement of chronic pain [16]. However, this study investigated the reliability and validity of the WBPQ on acute post-operative pain. Thereby providing evidence of its reliability and validity as a measure of acute pain. The results on the reliability and validity of the WBPQ also support some of the criteria on which pain intensity scales have been judged. The scale should:

(a) Detect treatment effects.

(b) assess various aspects of pain (acute and chronic) and

(c) Correspond with other pain measures [36-38].

(d) The major implication of this study is that the WBPQ can be used across cultures as a reliable and valid measure of pain. Provided the necessary adaptations are made. such as:

(e) translating it into the language used by the intended target group and

(f) Adapting the intensity scales from numbers to analogue scales with a pointer.

\section{The relationship between pre-surgical mood states and post-} operative pain

(g) This study failed to establish a relationship between pre-operative mood states in pre-laparotomy patients and the intensity of their surgical pain. Previous studies established a relationship between pre-surgical anxiety and post-operative pain [39-41,12,13,42].

(h) However, the POMS were found to not be able to differentiate various mood states in Setswana and Northern Sesotho speaking patients. Possibly due to the language of distress as used by Setswana and Northern Sesotho participants. Until this issue of the divergent validity of the POMS for both Setswana and Northern Sesotho speaking participants is cleared up by the future research, a conclusion as to the presence or not of a relationship between pre-operative mood states and post-operative pain must be put on hold.

\section{Conclusion and Recommendations}

Based on the findings of this study. It can be concluded that the WBPQ is a sensitive, reliable and valid measure of pain for both Setswana and Northern Sesotho speaking participants. It is able to detect treatment effects reflecting the effects of prescribed pain medication. It is recommended that:

(a) A test for assessing emotional states in Setswana and Northern Sesotho speaking people with no formal education and those with minimal education be constructed using a lay person's conceptions of emotional distress.

(b) A large enough sample is used in this research to justify the use of maximum likelihood factor analysis.

\section{Acknowledgements}

This study constituted part of a D.Litt et Phil submitted to the University of South Africa.

\section{References}

1. Melzack R, Wall PD (1965) Pain mechanisms: A new theory. Science 150 971-979.

2. Melzack R (1990) Phantom limbs and the concept of a neuromatrix. Trends Neurosci 13: 88-92.

3. Melzack R (1993) Pain: past, present and future. Can J Exp Psychol 47: 615629.

4. Melzack R (1999) From the gate to the neuromatrix. Pain 6: S121-S126

5. Hill HE, Kornetsky CH, Flanary HG, Wikler A (1952) Studies on anxiety associated with anticipation of pain: Effects of morphine. AMA Arch Neurol Psychiatry 67: 612-619.

6. Green EE, Green AM (1984) Coping effectively with invasive medical procedures. Journal of psychosocial oncology 5: 93-119.

7. Kent JC (1984) Anxiety and its relation to pain. Journal of Consulting and Clinical Psychology. 51: 872-876.

8. Schumacher D, Velden FL (1984) The psychopharmacology of pain. Journal of Clinical Psychiatry 43: 14-20.

9. Weisenberg M, Aviram JR, Wold D (1984) Personal control over aversive stimuli and its relationship to pain and stress. Psychological Bulletin 80: 286303.

10. Grimmer-Somers K., Vipond N, Kumar S, Hall G (2009) A review and critique of assessment instruments for patients with persistent pain. J Pain Res 2: 21-47.

11. Rhudy JL, Meagher MW (2003) Negative affect: effects on an evaluative measure of human pain. Pain 104: 617-626

12. Chapman CR, Cox GB (1977) Anxiety, pain and depression surrounding elective surgery: A multivariate comparison of abdominal surgery patients with kidney donors and recipients. J Psychosom Res 21: 7-15.

13. Scott EL, Clum GA, Peoples JB (1983) Pre-operative predictors of postoperative pain. Pain 15: 283-293.

14. EC Huskisson (1974) Measurement of pain. Lancet 304: 1127-1131. 
Citation: Mokhuane EQ (2011) The Effect of Mood on Post-Operative Pain and the Reliability and Validity of the Wisconsin Brief Pain Questionnaire Adapted on Black South Africans. J Neurol Neurophysiol 2:113. doi:10.4172/2155-9562.1000113

Page 7 of 7

15. Daut RL, Cleeland CS (1982) The prevalence and severity of pain in cancer. Cancer 50: 1913-1918.

16. Daut RL, Cleeland CS, Flanery RC (1983) Development of questionnaire of the Wisconsin Brief Pain Questionnaire to assess pain in Cancer and other diseases. Pain 17: 197-210.

17. Stinson JN, Kavanagh T, Yamada J, Gill N, Stevens B (2006) Systematic review of the psychometric properties. Interpretability and feasibility of self-report pain intensity measures for use in clinical trials in children and adolescents. Pain 125: 143-157.

18. Zwakhalen SM, Hamers JP, Berger MP (2006) The psychometric quality and clinical usefulness of three pain assessment tools for elderly people with dementia. Pain 126: 210-220.

19. Grimmer-Somers K., Vipond N, Kumar S, Hall G (2009) A review and critique of assessment instruments for patients with persistent pain. J Pain Res 2: 21-47.

20. Mc Nair DM, Lorr M, Droppelman LF (1971) Profile of Mood States (POMS) San Diego: Education and Industrial Testing Service.

21. McCorkle R, Quint-Benoliel J (1983) Symptom distress. current concerns and mood disturbance after diagnosis of life threatening disease. Social Science and Medicine 17: 431-438.

22. Norcross JC, Guadagnoli E, Prochaska JO (1984) Factor structure of the profile of mood states. (POMS): Two partial replications. J Clin Psychol 40: 12701277.

23. Schachter S, Reinhardt LC, Raubertas RF, Cleeland CS (1983) Emotional States of pain. Inter-individual measures of association. Journal of Behavioural Medicine 6: 405-418.

24. Woodforde JM, Merskey H (1972) Some relationships between subjective measures of pain. Journal of Psychosomatic Research 16: 173-178.

25. Scott J, Huskisson EC (1976) Vertical or horizontal visual analogue scales. Ann Rheum Dis 38: 560.

26. Turner JA, Romano JM (1992) Evaluating psychologic interventions for chronic pain: Issues and recent developments. Recent advances in the management of pain. Raven Press, New York.

27. Abu-Saad H (1984) Assessing children's responses to pain. Pain 19: 163-174.
28. Gracely RH. Psychophysical assessment of human pain. Advances in pain research and therapy. Raven Press. New York.

29. Tyler DC, Tu A, Douthit J, Chapman CR (1993) Toward validation of pain measurement tools for children: a pilot study. Pain 52: 301-309.

30. Migdal M, Chudzynska-Pomianowska E, Vause E, Henry E, Lazar J (2005) Rapid needle-free delivery of lidocaine for reducing the pain of venipuncture among pediatric subjects. Pediatrics 115: 393-398.

31. Brunelli C, Zecca E, Martini C, Campa T, Fagnoni E, et al. (2010) Comparison of numerical and verbal rating scales to measure pain exacerbations in patients with chronic cancer pain. Health Qual Life Outcomes 8: 42.

32. Hays WL (1963) Statistics. Holt Rinehart \& Winston. New York.

33. Winer BJ (1971) Statistical principles in experimental design. McGraw-Hill. New York.

34. Lorr M, Daston P, Smith IR (1967) An analysis of mood states. Educational and Psychological Measurement 27: 89-96.

35. Leff JP (1978) Psychiatrists versus patient's concepts of unpleasant emotions. Br J Psychiatry 133: 306-313.

36. Cronbach BC (1984) Statistical methods in psychology. Mc Craw Hill. New York.

37. Anastasi C (1990) Essentials of psychological measurement. Raven Press New York.

38. White $P$ (1993) Pain measurement. Principles and practice of pain Management McGraw-Hill. New York.

39. Andrew JM (1970) Recovery from surgery, with and without preparatory instructions, for three coping styles. J Pers Soc Psychol 15: 223-226.

40. EJ Langer, IL Janis, JA Wolfer (1975) Reduction of psychological stress in surgical patients. Journal of Experimental Social Psychology 11: 155-166.

41. Martinez-Urrutia A (1975) Anxiety and pain in surgical patients. Journal of Experimental Social Psychology 43: 437-442.

42. Kalkman CJ, Visser K., Moen J, Bonsel GJ, Grobbee DE, et al. (2003) Preoperative prediction of severe postoperative pain. Pain 105: 415-423. 